[Agr. Biol. Chem., Vol. 27, No. 1, p. 56 59, 1963]

\title{
Studies on the Flavor of Green Tea
}

\author{
Part IV. Dimethyl Sulfide and its Precursor \\ By Toshiko Kiribuchi and Tei Yamanishı \\ Laboratory of Food Chemistry, Ochanomizu University, Tokyo \\ Received September 14, 1962
}

\begin{abstract}
With an assumption that the laver-like odor of green tea is due to dimethyl sulfide, an attempt to isolate dimethyl sulfide from commercial green tea was made, and the identification of dimethyl sulfide was successful by making the co-ordinated compound with mercuric chloride, $2\left(\mathrm{CH}_{3}\right)_{2} \mathrm{~S} \cdot 3 \mathrm{HgCl}_{2}$. In addition, the presence of methylmethionine sulfonium salt in tea extract as a precursor of dimethyl sulfide was examined.
\end{abstract}

Sulfur compounds in green tea had been studied previously ${ }^{1}$ in our laboratory, and it was found that a large amount of hydrogen sulfide was evolved by heating the green tea with water. At the same time, dimethyl sulfide seemed to be present in the vapor because of its characteristic laver-like odor, although it could not be detected. Dimethyl sulfide has been isolated from various plants, including bracken (Pteridium aquilinum) and several species of Equisetum, especially in buds or young plants.

On the other hand, dimethyl- $\beta$-propiothetine $^{2)}$ and sulfonium compound ${ }^{3 \sim 5)}$ have been found as the precursor of dimethyl sulfide in algae and various plant species. Decomposition of the dimethyl- $\beta$-propiothetine yielded dimethyl sulfide, acrylic acid and $\mathrm{H}^{+}$.

McRorie et al. $(1954)^{6)}$ reported the existence in cabbage juice of a methionine analog,

1) M. Tsujimura, T. Yamanishi, R. Akiyama and S. Tanaka, $J$. Agr. Chem. Soc. Japan, 29, 145 (1955).

2) F. Challenger and M.I. Simpson, J. Chem. Soc., 1591 (1948).

3) R. Bywood, F. Challenger, D. Leaver, and M.I. Whitaker, Biochem. J., 48, XXX (1951).

4) F. Challenger, R. Bywood, P. Thiomas, and B.J. Hayward, Arch. Biochem. Biophys., 69, 514 (1957).

5) P. Karrer and C.H. Engster, Helv. Chem. Acta, 32, 957 (1949).

6) R. McRorie, C.L. Sutherland, M.S. Lewis, A.D. Barton, M.R. Glazener, and W. Shivc, J. Am. Chem. Soc., 76, 115 (1954). isolated as the methylmethionine sulfonium salt, which was considered to be a possible precursor of both methionine and dimethyl$\beta$-propiothetine mentioned above. At about the same time, Challenger et al. (1954) ${ }^{7)}$ identified a methylmethionine sulfonium salt in an asparagus extract. Decomposition of the methylmethionine sulfonium salt yielded homoserine and the characteristic odor of dimethyl sulfide, which can be shown by the following forms,

$$
\begin{aligned}
& \left(\mathrm{CH}_{3}\right)_{2} \stackrel{+}{\mathrm{S}} \mathrm{CH}_{2} \mathrm{CH}_{2} \mathrm{CH}\left(\mathrm{NH}_{2}\right) \mathrm{COOH} \rightarrow \\
& \left(\mathrm{CH}_{3}\right)_{2} \mathrm{~S}+\mathrm{CH}_{2}(\mathrm{OH}) \mathrm{CH}_{2} \mathrm{CH}\left(\mathrm{NH}_{2}\right) \mathrm{COOH} \\
& \left(\mathrm{CH}_{3}\right)_{2} \stackrel{+}{\mathrm{S}}-\mathrm{CH}_{2} \mathrm{CH}_{2} \mathrm{COOH} \rightarrow\left(\mathrm{CH}_{3}\right)_{2} \mathrm{~S}+ \\
& \mathrm{CH}_{2}=\mathrm{CHCOOH}+\mathrm{H}^{+}
\end{aligned}
$$

The present investigation involves the isolation and identification of dimethyl sulfide, which seemed to be a laver-like odorous substance in green tea, and methylmethionine sulfonium salt, a precursor of dimethyl sulfide.

\section{EXPERIMNTAL}

\section{Isolation and Identification of Dimethyl Sulfide in Green Tea.}

Commercial green tea $(800 \mathrm{~g}$, the highest quality) was pulverized and divided into eight $100 \mathrm{~g}$ portions.

7) F. Challenger and B.J. Hayward, Chem. \& Ind., 25, 729 (1954). 


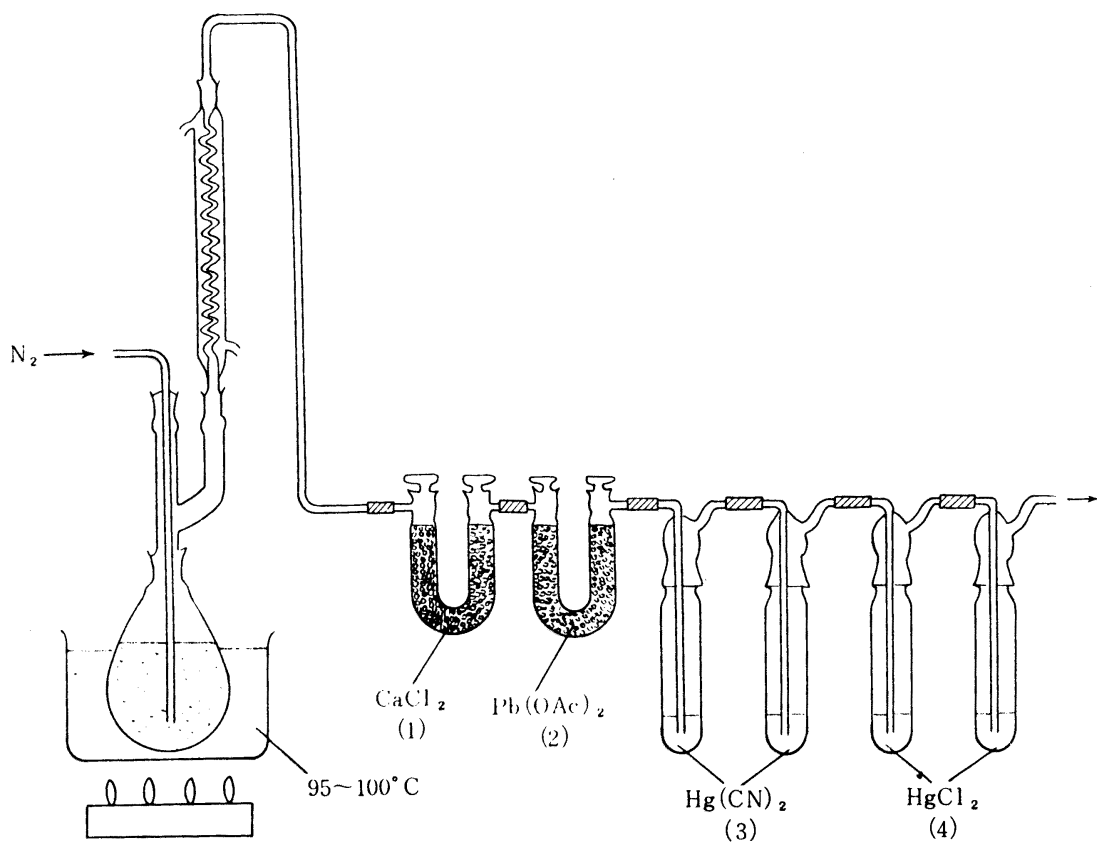

FIG. 1. Absorption Apparatus for Volatile Sulfur Compounds.

Each portion was put into a 1 liter flask with $800 \mathrm{ml}$ of water, and a stream of nitrogen was passed into the flask which was heated at $95 \sim 100^{\circ} \mathrm{C}$ in a water bath. The vapor evolved during heating for $1.5 \mathrm{hrs}$. was passed successively through calcium chloride (trap 1), lead acetate (trap 2), half saturated mercuric cyanicle (trap 3) and half saturated mercuric chloride (trap 4). This apparatus is shown in Fig. 1. Here, trap (2) served for the prior removal of hydrogen sulfide, and $\operatorname{tra}_{1}$ ' (3) served to remove mercaptans. If dimethyl sulfide was contained in the vapor, coordinated compound $2\left(\mathrm{CH}_{3}\right)_{2} \mathrm{~S} \cdot 3 \mathrm{HgCl}_{2}$ should be produced in trap (4). These four traps were used eight times without renewing the trapping reagent. Trap (4) became cloudy at the end of heating of the first portion and the white precipitate was formed remarkably at the end of heating of the eighth portion.

The white precipitate obtained was then separated from the mother liquid. After having been washed with water to remove any mercuric chloride accompanied, the white precipitate was dried in a desiccator.

2. Isolation of Methylmethionine Sulfonium Salt from Green Tea Extract.

The method of McRorie et a1. ${ }^{6)}$ was employed basically to isolate methylmethionine sulfonium salt;
$800 \mathrm{ml}$ of cold water was added to $200 \mathrm{~g}$ of the same powdered green tea as discribed above. After being kept in cold overnight, it was filtered through a bag filter and about $470 \mathrm{ml}$ of the cloudy extract was obtained. For removal of tannins the extract was treated with acidic solution of gelatine, filtered and neutralized. Finally, about $800 \mathrm{ml}$ of clear solution was obtained. The solutoin was then percolated over IRC-50 resin which had been converted to the ammonium form by treatment with $1 \mathrm{~N}$ acetic acid. Elution was accomplished just after the eluate became acidic. Eluate was concentrated under reduced pressure at $40 \sim 50^{\circ} \mathrm{C}$ and dried in vacuo, and excess ammonium acetate was removed by sublimation under reduced pressure at $40 \sim 50^{\circ} \mathrm{C}$, until about $38 \mathrm{~g}$ of the solids were obtained.

Solid (38 g) was then suspended in $200 \mathrm{ml}$ of methanol with stirring. Insoluble material $(0.7 \mathrm{~g})$ was removed by centrifugation, washed with two $10 \mathrm{ml}$ portions of methanol and discarded. Isopropyl alcohol $(1100 \mathrm{ml})$ was added to the combined supernatant and washings and kept in cold for three or four hours to complete preciptation. The precepitate (20 g) was removed by centrifugation and discarded. The alcohol fraction obtained was absorbed on alumina when the 
centrifugate was percolated through a column prepared as a slurry in methanol (6 $\mathrm{g}$ of alumina per $\mathrm{g}$ of solids). The column was washed successively with $300 \mathrm{ml}$ portions of methanol, $75 \%$ methanol and $50 \%$ methanol. Elution was accomplished wtih water. The aqueous fraction was combined and filtered through celite to remove suspended alumina. The filtrate was concentrated under reduced pressure at $40 \sim 50^{\circ} \mathrm{C}$, and the concentrated solution was subjected to paper chromatography.

\section{Paper Chromatography.}

The concentrate mentioned above was tested by paper chromatography and compared with synthetic methylmethionine sulfonium chloride. Every paper chromatography was run on Toyo-Roshi No. 51 filter paper. Solvent systems were $65 \%$ pyridine, $n$-butanolacetic acid-water $(4: 1: 1)$ and $90 \%$ phenol (in ammonia vapor). Spots on the chromatograms were detected with ninhydrine.

\section{RESUTLTS AND DISCUSSION}

The white precipitate produced in trap (4) (Fig. 1) melted at $157 \sim 158^{\circ} \mathrm{C}$ and corresponded to the melting point of the co-ordinated compound prepared from authentic dimethyl sulfide. No depression in m.p. of mixture was observed. Thus the white precipitate was identified as pure $2\left(\mathrm{CH}_{3}\right)_{2} \mathrm{~S}$ $3 \mathrm{HgCl}_{2}$. It was also found that the amount of dimethyl sulfide evolved from the green tea powder cluring heating at $95 \sim 100^{\circ} \mathrm{C}$ for 1.5 hrs. was about 0.25 p.p.m. of the green tea. A small amount of dimethyl sulfide seems to participate to some extent in flavor of green tea because of its powerful odor. (It is known that the threshold value of dimethyl sulfide is about $10^{-7}$.)

From the results of paper chromatography of methylmethionine sulfonium salt isolated from the green tea extract, the presence of methylmethionine sulfonium salt in green tea was recognized as shown in Fig. 2. On the chromatogram of methylmethionine sulfonium chloride heated at $100^{\circ} \mathrm{C}$ for $30 \mathrm{~min}$. (presented as D), a spot of homoserine, besides that of methylmethionine sulfonium chloride appeared. Homoserine is known to

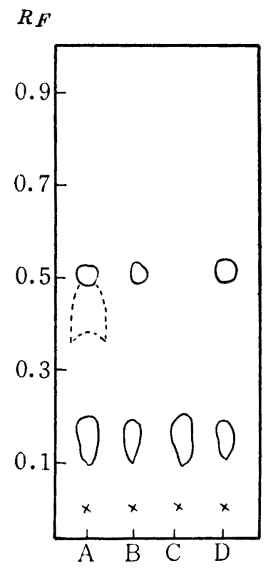

(I)

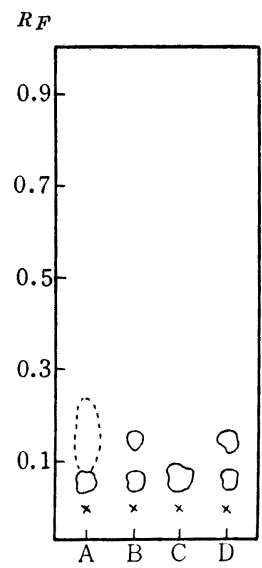

(II)

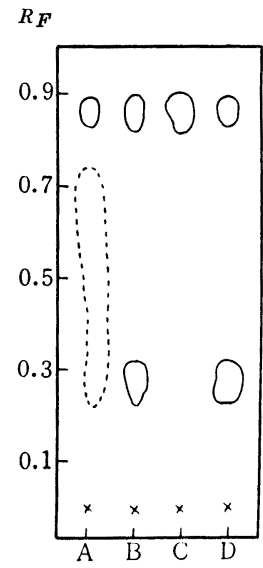

(III)

FIG.2. Paper Chromatograms of the Isolate from Tea Extract and Methylmethione Sulfonium

Solvent System : $\quad$ (I), $65 \%$ Pyridine. Chloride.

(II), $n$-Butanol-Acetic Acid-Water $(4: 1: 1)$

(III), $90 \%$ Phenol (in ammonia vapor).

A : The isolate from tea extract.

B : Control (solution of synthetic methylmethionine sulfonium chloride which was subjected to the same treatment as tea extract).

C: Methylmethionine sulfonium chloride.

D: Heat treated methylmethionine sulfonium chloride. 
be a degradation product of methylmethionine sulfonium salt. The spot of homoserine was also found in the green tea extract. In every case by using the three kinds of solvents a large unknown spot (a dotted line in Fig. 2) was found on the chromatograms of the green tea extract. Attempts to determine the composition of the spot, even after separation by two-dimensional paper chromatography and paper electrophoresis, were unsuccessful.

\section{SUMMARY}

1. The presence of dimethyl sulfide as a flavor component of green tea was confirmed by means of collecting it as a co-ordinated compound $2\left(\mathrm{CH}_{3}\right)_{2} \mathrm{~S} \cdot 3 \mathrm{HgCl}_{2}$. The amount of dimethyl sulfide evolved from the green tea heated with water at $95 \sim 100^{\circ} \mathrm{C}$ for $1.5 \mathrm{hrs}$. was about 0.25 p.p.m. of the green tea.

2. Methylmethionine sulfonium salt was found in the green tea extract by paper chromatography as a precursor of dimethyl sulfide. 